\title{
Usulan Strategi Bauran Pemasaran untuk Meningkatkan Frekwensi Kedatangan Konsumen ke RM. Swieke Ibu Kristina, Karawang Barat
}

\author{
Marketing Strategy Proposal to Enhance Consumer's Arrival Frequency \\ to RM. Swieke Ibu Kristina, West Karawang
}

\author{
Yulianti, Stevan \\ Program Studi Teknik Industri, Fakultas Teknik, Universitas Kristen Maranatha, Bandung \\ E-mail: yulianti@eng.maranatha.edu, stevanvanzoey94@ gmail.com
}

\begin{abstract}
Abstrak
RM. Swieke Ibu Kristina yang sudah berdiri sejak 12 tahun yang lalu memiliki lokasi yang sangat strategis di Karawang, namun selama 4 tahun terakhir mengalami penurunan omzet penjualan sebesar rata-rata $8 \%$ per tahun.

Pengumpulan data dilakukan dengan cara menyebarkan kuesioner yang mengacu pada model penelitian Marketing Mix yaitu bauran pemasaran 7P, teori segmentasi-targeting-positioning, dan teori perilaku organisasi. Kuesioner penelitian disebarkan pada 120 orang konsumen RM. Swieke Ibu Kristina.

Data mengenai kepentingan konsumen dihitung besar persentase kepentingannya dan menyisakan 43 buah variabel pemasaran yang dipentingkan oleh responden. Setelah data yang diperoleh dari kuesioner terbukti valid dan reliabel, selanjutnya dilakukan pengolahan Regresi Berganda dengan variabel kinerja pemasaran RM. Swieke Ibu Kristina sebagai variabel independen dan frekwensi kedatangan konsumen sebagai variabel dependen. Data mengenai tingkat kepentingan konsumen dalam memilih rumah makan swieke dan persepsi konsumen mengenai performasi RM. Swieke Ibu Kristina diolah menggunakan pengujian hipotesis ratarata. Informasi mengenai profil konsumen digunakan untuk usulan targeting dan positioning yang tepat bagi RM. Swieke Ibu Kristina dan mempertajam usulan penelitian.

Prioritas perbaikan utama diberikan pada variabel kinerja pemasaran yang secara signifikan berpengaruh terhadap frekwensi kedatangan konsumen ke RM. Swieke Ibu Kristina, dilanjutkan dengan variabel yang belum memuaskan konsumen. RM. Swieke Ibu Kristina disarankan untuk memposisikan diri rumah makan keluarga yang mementingkan kualitas rasa. Saran perbaikan berdasarkan hasil penelitian yaitu penambahan meja dan kursi yang nyaman, memberikan pelatihan pada karyawan mengenai seluruh menu restoran yang ada, penggunaan pakaian seragam, membuat menu pemesanan yang dicetak untuk meminimasi kesalahan, penggunaan tirai panjang untuk mencegah debu yang masuk, dan lain-lain.
\end{abstract}

Kata kunci: Bauran pemasaran, perilaku organisasi, regresi berganda, pengujian hipotesis

\begin{abstract}
RM. Swieke Ibu Kristina stood since 12 years ago. RM. Swieke Ibu Kristina has a very strategic location in Karawang, but for the last 4 years the sales decreased with average of $8 \%$ per year.

Questionnaires refer to Marketing Mix model (7P), segmentation-targeting-positioning theory, and organizational behavior theory. The research questionnaire distributed to 120 consumers. Consumer's importance level calculated and leaves 43 marketing variables. After the data obtained from the questionnaires proved valid and reliable, multiple regression method performed with RM. Swieke Ibu Kristina's performance as independent variables and consumer's arrival frequency as dependent variable. Consumer's importance level and RM. Swieke Ibu Kristina's performance processed using hypothesis testing for means. Information about consumer profiles used for targeting and positioning proposals for RM. Swieke Ibu Kristina and sharpen the research proposal.

The main improvement priorities given on variables that significantly affect consumer's arrivals frequency, followed by variables that have not satisfied consumers. RM. Swieke Ibu Kristina advised to position itself as a family restaurant that emphasizes the taste quality.
\end{abstract}


Improvements suggested based on are the addition of comfortable tables and chairs, employee's training, employee's uniform, creating a printed ordering menu to minimize errors, use long curtains to prevent dust, etc.

Keywords: Marketing Mix, consumer behaviour, multiple regression, hypothesis testing

\section{Pendahuluan}

Swieke adalah menu masakan Tionghoa Indonesia yang cukup banyak disukai masyarakat Indonesia. Walaupun belum selazim daging ayam atau sapi, namun cukup banyak orang yang menjadikan swike ini sebagai makanan favorit mereka.

Rumah makan Swieke yang dimiliki Ibu Kristina berdiri 12 tahun yang lalu, di jalan Interchange Tol Karawang Barat. Lokasi rumah makan ini sangat strategis karena berada di jalan utama akses Tol Karawang Barat yang banyak dilalui karyawan dan juga dekat dengan dua perumahan. Jalan utama akses Tol Karawang Barat merupakan salah satu akses masuk orang-orang dari luar kota untuk masuk Karawang. Walaupun memiliki lokasi strategis, namun rumah makan ini mengalami penurunan omset penjualan rata-rata sebesar $8 \%$ setiap tahunnya selama 4 tahun terakhir, dan hal ini merisaukan Ibu Kristina sebagai pemilik rumah makan.

Ibu Kristina membutuhkan strategi pemasaran yang tepat bagi RM. Swieke Ibu Kristina yang mampu membantu peningkatan penjualan, dengan memanfaatkan informasi mengenai perilaku konsumen dalam membeli swieke dan variabel-variabel yang signifikan berpengaruh terhadap frekwensi kedatangan konsumen di RM. Swieke Ibu Kristina, juga berdasarkan targeting dan positioning yang tepat bagi RM.Swieke.

\section{Tinjauan Pustaka}

Tinjauan pustaka ini berisi teori-teori yang digunakan dalam penelitian, yang dijadikan dasar kerangka berpikir dan landasan dalam pengolahan data serta penganalisaan hasil pengolahan data.

\subsection{Bauran Pemasaran (Kotler, Amstrong, 2001)}

Bauran pemasaran adalah seperangkat alat pemasaran yang digunakan oleh perusahaan untuk mengejar tujuan pemasarannya pada pasar sasaran. Bauran pemasaran terdiri dari product, price, place, promotion, people, process, dan physical evidence. Umumnya pada penelitian pemasaran produk, bauran pemasaran lebih dikenal dengan 4P (Product, Price, Place, dan Promotion). Dalam pemasaran jasa, terdapat tambahan 3P yaitu People, Process, dan Physical Evidence.

- Product (produk) adalah tawaran nyata perusahaan untuk pasar, yang mencakup kualitas, desain, fitur, merek, dan kemasan produk. Produk adalah sesuatu yang langsung dapat dirasakan atau dinikmati oleh konsumen, sehingga pengendalian terhadap suatu produk sangat penting dilakukan secara berkelanjutan."

- Price (harga) adalah sejumlah uang yang harus dikeluarkan konsumen untuk memperoleh produk yang ditawarkan. Beberapa konsumen tidak keberatan untuk mengeluarkan uang lebih jika kualitas barang atau jasa yang mereka dapatkan dirasakan sebanding. Hal ini bisa disebabkan persepsi konsumen yang menilai kualitas suatu barang atau jasa dari sudut pandang nilai harganya sehingga harga sering menjadi alat untuk menjalin hubungan dengan konsumen dan digunakan sebagai alat untuk bersaing dalam merebut pangsa pasar.

- Place (tempat/lokasi) adalah tempat di mana suatu produk atau jasa diproduksi, ditawarkan, dan dapat ditemukan oleh konsumen. Pemilihan lokasi perusahaan sering menjadi keputusan yang sangat penting karena biasanya konsumen berbelanja di tempat yang terdekat dari tempat tinggal mereka. Lokasi dapat digunakan untuk mengembangkan keunggulan bersaing 
perusahaan, sehingga pemilihan lokasi yang tepat adalah lokasi yang dapat menjangkau konsumen yang menjadi pasar sasarannya.

- Promotion (promosi) merupakan aktivitas yang dilakukan sebagai bentuk usaha dengan tujuan mengomunikasikan produk atau jasa dalam menyebarkan informasi, mempengaruhi, dan mengetahui keberadaan produk atau jasa dengan tujuan agar konsumen bersedia menerima, membeli, dan loyal pada produk atau jasa yang ditawarkan perusahaan tersebut.

- People (manusia) merupakan unsur paling penting dalam perusahaan jasa, yaitu penyedia jasa dari perusahaan kepada pelanggan karena unsur ini akan memberikan persepsi terhadap kualitas jasa secara keseluruhan.

- Process (proses) adalah seluruh usaha perusahaan dalam menjalankan aktivitasnya, untuk memenuhi kebutuhan dan keinginan konsumen. Proses yang efisien dapat menjadi keunggulan kompetitif bagi perusahaan jasa.

- Physical Evidence (bukti fisik) merupakan lingkungan fisik dan unsur berwujud dimana penyedia jasa dan pelanggan berinteraksi. Unsur ini dapat digunakan untuk menguatkan positioning dan citra serta mengembangkan produk surround.

\subsection{Proses Keputusan Pembelian (Kotler, Keller, 2009)}

Dalam pengambilan keputusan membeli, proses psikologis dasar berperan penting, sehingga perusahaan perlu memahami tahapan-tahapan proses tersebut. Lima tahap yang dilalui oleh konsumen dalam pengambilan keputusan untuk membeli suatu produk/jasa, yaitu sebagai berikut:

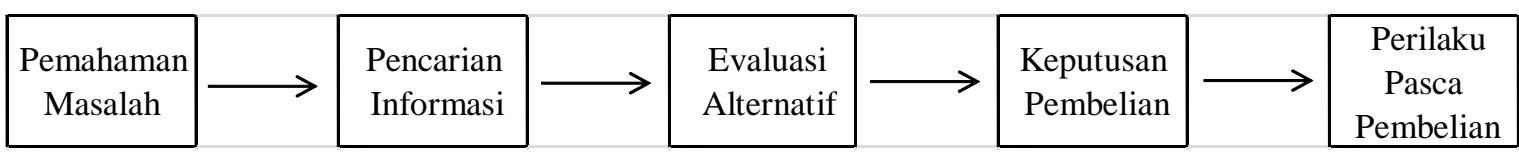

Gambar 1. Proses Keputusan Pembelian

\subsection{Regresi Berganda (Hair, 2006)}

Regresi berganda adalah teknik statistika yang digunakan untuk meneliti hubungan antara satu variabel dependen (kriteria) dan beberapa (dua atau lebih) variabel independen (prediktor), juga untuk memprediksi 1 variabel dependen. Metode ini paling banyak digunakan dalam pengambilan keputusan bisnis, yaitu untuk mencari hubungan faktor/faktor-faktor terhadap outcome spesifik tertentu. Contoh dalam model peramalan bisnis, diprediksi ekonomi nasional berdasarkan level pendapatan, investasi bisnis dalam negeri dan luar negeri, pembayaran utang luar negeri, inflasi, dll, untuk diadaptasi dalam strategi marketing perusahaan. Regresi juga dapat digunakan untuk mempelajari bagaimana keputusan konsumen atau bentuk perilaku konsumen. Juga dapat digunakan untuk memperkirakan kelayakan produk baru, atau tingkat pengembalian produk.

Persamaan regresi berganda: $Y=b_{0}+b_{1} \cdot X_{1}+b_{2} \cdot X_{2}+\ldots+b_{n} . X_{n}+e$

Dimana :

$\begin{array}{ll}\mathrm{Y} & \text { : prediksi variabel dependen } \\ \mathrm{X}_{\mathrm{n}} & \text { : variabel independen } \\ \mathrm{b} & \text { : koefisien persamaan regresi } \\ \mathrm{b}_{1} \cdot \mathrm{X}_{1} & \text { : efek linier dari } \mathrm{X}_{1} \\ \mathrm{~b}_{2} \cdot \mathrm{X}_{2} & \text { : efek linier dari } \mathrm{X}_{2}\end{array}$

Persamaan regresi berganda yang terbentuk dapat digunakan untuk melakukan prediksi dan peramalan.Tanda positif/negatif pada koefisien persamaan regresi (b) menunjukkan arah hubungan antara variabel dependen dan variabel independen. Positif artinya arah hubungan searah sedangkan negatif berarti hubungan yang bertolak belakang. Besar nilai koefisien persamaan regresi (b) menunjukkan kekuatan hubungan antara variabel independen dan dependen, yaitu menunjukkan perubahan yang terjadi pada variabel dependen tiap kali variabel independen berubah sebesar 1 
unit, sehingga dapat diketahui variabel independen mana yang efeknya lebih besar terhadap variabel dependen.

Kekuatan hubungan antara variabel independen dan dependen ditunjukkan oleh nilai koefisien korelasi (R). Hubungan dikatakan cukup kuat apabila memiliki nilai minimum 0.4.

\subsection{Pengujian Hipotesis Rata-rata (Anderson, 2008)}

Uji hipotesis merupakan prosedur untuk pengambilan keputusan secara statistika, untuk memutuskan apakah menerima atau menolak hipotesis mengenai parameter yang telah dirumuskan. Salah satu bentuk pengujian hipotesis adalah pengujian hipotesis rata-rata dari 2 populasi independen.

$$
\begin{array}{ll}
\mathrm{H}_{\mathrm{o}} & : \mu_{1}=\mu_{2} \\
\mathrm{H}_{1} & : \mu_{1} \neq \mu_{2}
\end{array} \quad \text { atau } \quad \mu_{1}>\mu_{2} \quad \text { atau } \quad \mu_{1}<\mu_{2}
$$

Rumus yang digunakan :

$$
\mathrm{Z}=\frac{\left(\bar{x}_{1}-\bar{x}_{2}\right)-\left(\mu_{1}-\mu_{2}\right)}{\sqrt{\frac{\mathrm{s}_{1}^{2}}{\mathrm{n}_{1}}+\frac{\mathrm{s}_{2}^{2}}{\mathrm{n}_{2}}}}
$$

Dimana :

$$
\begin{aligned}
& \mu \text { : rata-rata populasi } \\
& \mathrm{x}: \text { rata-rata sampel } \\
& \mathrm{s}: \text { standard deviasi sampel } \\
& \mathrm{n}: \text { ukuran sampel }
\end{aligned}
$$

\section{Pembahasan}

\subsection{Penentuan Variabel Penelitian}

Untuk memahami proses pengambilan keputusan dalam pembelian, variabel penelitian dibuat untuk setiap tahap pengambilan keputusan yaitu :

1. Tahap pemahaman masalah : Tujuan pergi ke RM. Swieke Ibu Kristina

2. Tahap pencarian informasi : Sumber informasi mengenai RM. Swieke Ibu Kristina

3. Tahap evaluasi alternatif :

- Alternatif rumah makan penjual swieke yang menjadi bahan pertimbangan.

- Alasan utama pemilihan RM. Swieke Ibu Kristina

○ Harapan saat datang ke RM. Swieke Ibu Kristina

4. Tahap keputusan pembelian :

- Pengambil keputusan untuk memilih RM. Swieke Ibu Kristina

- Yang menemani saat berkunjung ke RM. Swieke Ibu Kristina

- Frekwensi makan di RM. Swieke Ibu Kristina

- Faktor penghambat yang menyebabkan pembatalan ke RM. Swieke Ibu Kristina

- Frekwensi terjadinya faktor penghambat.

5. Tahap perilaku pasca pembelian

- Apakah akan makan kembali di RM. Swieke Ibu Kristina?

- Apakah akan mengajak teman atau kerabat lainnya untuk makan di RM. Swieke Ibu Kristina?

Untuk penentuan targeting dan positioning, disusun variabel penelitian sebagai berikut:

1. Aspek Demografis :

○ Usia konsumen.

2. Aspek Geografis :

○ Lokasi tempat tinggal konsumen.

3. Aspek Psikografis :

○ Tujuan datang ke RM. Swieke Ibu Kristina. 


\section{USULAN STRATEGI BAURAN PEMASARAN (Yulianti, dkk.)}

\section{Aspek Perilaku :}

○ Pengetahuan mengenai keberadaan RM. Swieke Ibu Kristina.

- Rumah makan penjual swieke yang sering dikunjungi.

- Anggota kelompok dan jumlah anggota kelompok yang datang.

○ Frekwensi makan bersama kelompok per bulan.

Konsep bauran pemasaran digunakan sebagai dasar dalam penyusunan variabel untuk menilai tingkat kepentingan konsumen dan tingkat kinerja RM. Swieke Ibu Kristina, yaitu :

Product (Produk):

1. Keanekaragaman menu swieke yang ditawarkan

2. Keanekaragaman jenis minuman yang ditawarkan

3. Keanekaragaman cara memasak swieke ditawarkan

4. Penyajian swikee dalam bentuk pedas

5. Penyajian swikee masih panas

6. Kehalalan jenis kodok yang dimasak

7. Kelezatan makanan yang disajikan

8. Kebersihan makanan yang disajikan

9. Kebersihan bahan makanan yang disajikan

10. Kesegaran bahan makanan yang disajikan

11. Kesegaran bahan minuman yang disajikan

12. Variasi ukuran kodok yang ditawarkan

13. Variasi ukuran porsi makanan yang disajikan

14. Keanekaragaman makanan pendukung (saos sambal, saos tomat, dll.) yang disajikan

15. Konsistensi rasa makanan yang disajikan

16. Kemenarikan cara penyajian

Price (Harga):

17. Harga yang sesuai dengan porsi makanan yang ditawarkan

18. Harga yang sesuai dengan ukuran kodok yang ditawarkan

19. Harga yang bersaing dibandingkan dengan kompetitor

Place (Tempat):

20. Lokasi rumah makan yang mudah ditemukan

21. Lokasi rumah makan yang mudah dicapai

Promotion (Promosi):

22. Kemenarikan spanduk / papan nama rumah makan

23. Kemenarikan promosi melalui sosial media

24. Kemenarikan promosi melalui media elektronik (Radio, TV, dll)

People (Manusia):

25. Ketanggapan karyawan dalam melayani konsumen

26. Pengetahuan karyawan tentang menu makanan

27. Keramahan karyawan

28. Kesopanan karyawan

29. Kerapihan karyawan

30. Kemampuan karyawan dalam menjelaskan menu restoran

Process (Proses):

31. Kecepatan penyajian makanan

32. Kecepatan perhitungan proses pembayaran

33. Ketepatan dalam perhitungan harga

34. Kejelasan nota pembelian

35. Ketepatan dalam memberikan pengembalian uang kembali

36. Kerapihan proses pembungkusan

37. Lamanya jam operasional dibanding rumah makan swikee lainnya

Physical Evidence (Bukti fisik):

38. Area parkir luas

39. Kebersihan rumah makan

40. Kebersihan peralatan makan 
41. Kelengkapan peralatan makan

42. Kenyamanan meja dan kursi

43. Kecukupan jumlah meja dan kursi

44. Kenyamanan sirkulasi udara di tempat makan

45. Kemenarikan warna interior rumah makan

\subsection{Pengumpulan Data}

Data yang digunakan dalam penelitian ini dikumpulkan melalui dua kali penyebaran kuesioner, yaitu kuesioner pendahuluan dan kuesioner penelitian:

1. Kuesioner pendahuluan berisi variabel penelitian dari bauran pemasaran dengan skala Guttman (Penting atau Tidak Penting). Bagian ini bertujuan untuk menyaring variabel bauran pemasaran yang dipentingkan oleh konsumen. Hanya variabel bauran pemasaran yang dinilai penting oleh konsumen yang akan digunakan dalam kuesioner penelitian.

Kuesioner pendahuluan ini disebarkan pada 50 orang responden, dengan metode sampling Nonprobability Sampling yaitu Purposive Sampling, yaitu pada konsumen yang pernah makan di rumah makan swieke secara umum minimal 3 kali dan berusia minimal 18 tahun dengan pertimbangan agar konsumen sudah dapat mengisi kuesioner dengan baik dan benar. Kuesioner disebarkan di sekitar RM. Swieke Ibu Kristina, di sekitar Jl. Interchange Tol Karawang Barat, dan di sekitar Karawang Kota.

Kuesioner pendahuluan diolah menggunakan metode persentase. Variabel yang dianggap penting adalah variabel yang memiliki nilai persentase jawaban penting minimum $50 \%$, dan akan dijadikan variabel untuk kuesioner penelitian.

2. Kuesioner penelitian, terdiri dari 2 bagian yaitu:

- Bagian pertama berisi data responden dengan variabel penelitian untuk segmentasitargeting-positioning dan tahap pengambilan keputusan pembelian.

- Bagian kedua berisi pengukuran tingkat kepentingan konsumen (skala Likert Sangat Tidak Penting hingga Sangat Penting / 1 hingga 4) dan pengukuran performansi RM. Swieke Ibu Kristina (skala Likert Sangat Tidak Baik hingga Sangat Baik / 1 hingga 4).

Penentuan jumlah sampel minimum kuesioner penelitian menggunakan metode proporsi, karena ukuran populasi tidak dapat diketahui secara pasti, dengan rumus:

$$
\mathrm{N}=\left(\frac{\mathrm{Z}_{\alpha / 2}}{\mathrm{e}}\right)^{2} \cdot \mathrm{P} \cdot(1-\mathrm{P})
$$

\section{Dimana :}

$\mathrm{N} \quad=$ Ukuran sampel.

$\mathrm{Z}=$ Standar score $\alpha$ untuk yang dipilih, dilihat dari tabel Normal.

$\mathrm{e}=$ Sampling error maksimum yang diperkenankan

$1-\alpha=$ Tingkat kepercayaan $(95 \%)$

$\alpha=$ Tingkat ketelitian $(5 \%)$

$\mathrm{P}=$ Proporsi populasi yang akan diteliti. Jika tidak dapat memperkirakan proporsi populasi, maka ditentukan $\mathrm{P}=0.5$.

Sehingga :

$\mathrm{N}=\left(\frac{1.96}{0.01}\right)^{2} \cdot 0.5 .(1-0.5)=96.04$ responden $\approx 97$ responden

Jumlah responden minimal adalah 97 responden, namun dengan pertimbangan kemungkinan adanya pengisian kuesioner yang tidak lengkap maka akan disebarkan kuesioner sebanyak 120 kuesioner. 
Kuesioner penelitian disebarkan di RM. Swieke Ibu Kristina dengan metode sampling Nonprobability Sampling yaitu Purposive Sampling, yaitu pada konsumen berusia minimal 18 tahun yang sedang makan di RM. Swieke Ibu Kristina dan minimal pernah makan di rumah makan swieke secara umum sebanyak 3 kali.

\subsection{Pembahasan}

\subsubsection{Pengolahan Kuesioner Pendahuluan}

Kuesioner pendahuluan diolah dengan metode persentase, menunjukkan bahwa ada 2 variabel penelitian yang tidak dipentingkan oleh konsumen yaitu : variabel 23 (Kemenarikan promosi melalui sosial media) dengan persentase jawaban kepentingan $23.33 \%$ dan variabel 24 (Kemenarikan promosi melalui media elektronik (radio, TV, dll)) dengan persentase jawaban kepentingan $13.33 \%$. Kedua variabel tersebut akan dihilangkan pada kuesioner penelitian.

\subsubsection{Pengolahan Kuesioner Penelitian}

Setelah dilakukan pemeriksaan terhadap kelengkapan pengisian kuesioner, ada 1 kuesioner yang tidak diisi dengan lengkap sehingga kuesioner tersebut tidak diolah lebih lanjut. Kuesioner penelitian yang akan diolah lebih lanjut adalah 119 kuesioner.

Setelah terbukti bahwa data hasil pengumpulan kuesioner penelitian valid (seluruh nilai $r>$ nilai $r$ minimum yaitu 0.18056) dan reliabel (nilai $\alpha>0.7$ ) maka data dapat diproses lanjut. Sesuai tujuan penelitian, dilakukan pengolahan data sebagai berikut:

1. Mengetahui variabel kinerja pemasaran RM. Swieke Ibu Kristina yang secara signifikan berpengaruh terhadap frekwensi kedatangan konsumen digunakan metode Regresi Berganda.

2. Mengetahui tingkat kepuasan konsumen akan RM. Swieke Ibu Kristina melalui pengujian hipotesis rata-rata dua populasi, menggunakan nilai tingkat kepentingan konsumen dan tingkat performansi RM. Swieke Ibu Kristina.

3. Mengusulkan targeting dan positioning yang tepat bagi RM. Swieke Ibu Kristina.

4. Menentukan prioritas strategi pemasaran yang harus dilakukan oleh RM. Swieke Ibu Kristina berdasarkan seluruh hasil pengolahan kuesioner penelitian yang telah dilakukan dan usulan targeting-positioning.

\section{A. Pengolahan Kuesioner Penelitian : Metode Regresi Berganda}

Dalam penelitian ini, metode Regresi Berganda digunakan untuk mengetahui pengaruh variabel kinerja pemasaran RM. Swieke Ibu Kristina (sebagai variabel independen) yang secara signifikan berpengaruh terhadap frekwensi kedatangan konsumen (variabel dependen).

Hasil pengujian ANOVA (Analysis of Variance) di bawah ini digunakan untuk memastikan ketepatan penggunaan metode Regresi Berganda.

Tabel 1. Tabel ANOVA

\begin{tabular}{|c|c|c|c|c|c|c|}
\hline Model & & $\begin{array}{l}\text { Sum of } \\
\text { Squares }\end{array}$ & df & Mean Square & $\mathrm{F}$ & Sig. \\
\hline & Regression & 51.941 & 5 & \multirow{3}{*}{$\begin{array}{r}10.388 \\
1.595\end{array}$} & \multirow[t]{3}{*}{6.511} & \multirow[t]{3}{*}{$.000^{\mathrm{am}}$} \\
\hline & Residual & 180.277 & 113 & & & \\
\hline & Total & 232.218 & 118 & & & \\
\hline
\end{tabular}

am. Predictors: (Constant), Var37, Var43, Var30, Var33, Var27

an. Dependent Variable: Frekdtg

Ho : Garis regresi tidak linier

$\mathrm{Hi}$ : Garis regresi linier 
Nilai signifikansi pada Tabel ANOVA diatas berada dibawah 0.05, artinya tolak Ho, garis regresi linier, sehingga metode Regresi Berganda cocok untuk digunakan dalam penelitian ini.

Tabel 2. Model Summary

\begin{tabular}{|l|c|r|r|r|}
\hline Model & R & R Square & $\begin{array}{c}\text { Adjusted R } \\
\text { Square }\end{array}$ & $\begin{array}{c}\text { Std. Error of } \\
\text { the Estimate }\end{array}$ \\
\hline 39 & $.473^{\text {am }}$ & .224 & .189 & 1.26308 \\
\hline
\end{tabular}

am. Predictors: (Constant), Var37, Var43, Var30, Var33, Var27

Dependent Variable: Frekdtg

Nilai $\mathrm{R}$ pada Tabel 2 diatas menunjukkan kekuatan hubungan antara variabel independen dan variabel dependen. Nilai $R=0.473$ memiliki arti bahwa kekuatan hubungan antara kedua variabel independen dan variabel dependen termasuk positif cukup kuat.

Dari nilai Koefisien Determinasi ( $R$ Square) dapat diketahui bahwa variabel kinerja RM. Swieke Ibu Kristina hanya dapat menjelaskan tentang frekwensi kedatangan konsumen sebesar $22.4 \%$, sisanya $77.6 \%$ dijelaskan oleh variabel-variabel lain yang tidak diteliti dalam penelitian ini.

Tabel 3. Coefficients

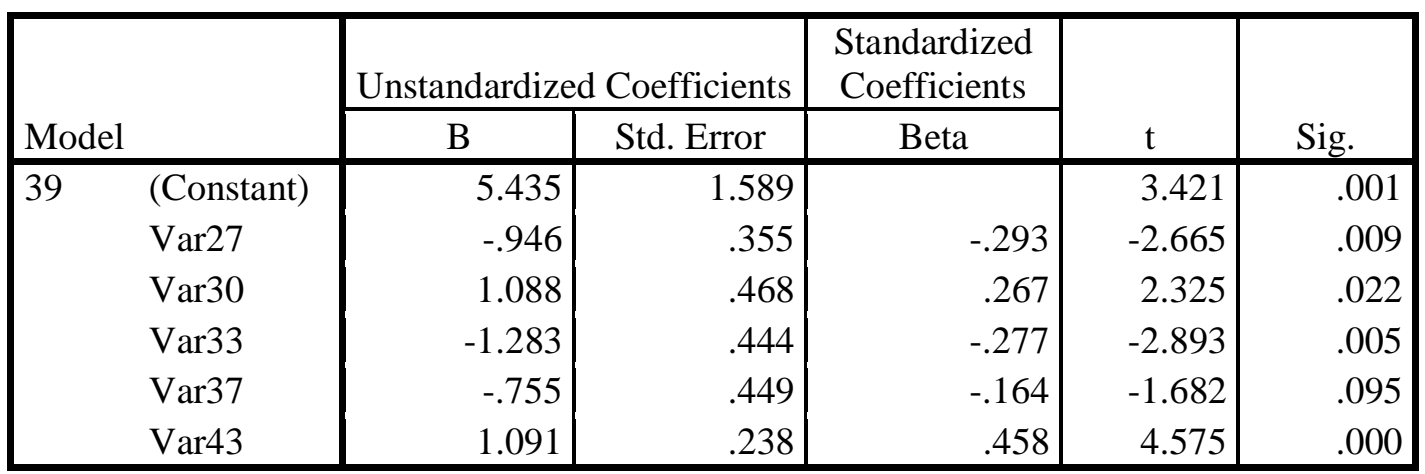

am. Dependent Variable: Frekdtg

Kolom B pada Tabel 3 diatas digunakan sebagai koefisien persamaan regresi. Variabel independen yang dimunculkan dalam persamaan regresi penelitian ini adalah variabel independen yang secara signifikan berpengaruh positif terhadap frekwensi kedatangan konsumen, ditunjukkan dengan nilai Signifikansi dibawah 0.05 .

Ho : Variabel independen tidak berpengaruh signifikan terhadap frekwensi kedatangan konsumen $(\beta=0)$

$\mathrm{Hi}$ : Variabel independen secara signifikan berpengaruh positif terhadap frekwensi kedatangan konsumen $(\beta>0)$

Variabel kinerja 30 dan kinerja 43 memiliki nilai signifikansi dibawah 0.05 dan bernilai koefisien positif sehingga keduanya dimasukkan dalam persamaan regresi berganda.

Persamaan regresi berganda yang terbentuk :

Frekwensi Kedatangan Konsumen $=5.435+1.088$ Var30 + 1.091 Var43

- Variabel kinerja 30 (Kemampuan karyawan dalam menjelaskan menu restoran) dan Variabel kinerja 43 (Kecukupan jumlah meja dan kursi) memiliki pengaruh positif terhadap frekwensi kedatangan konsumen, artinya semakin tinggi kemampuan menjelaskan karyawan dan semakin banyak jumlah meja dan kursi maka frekwensi kedatangan konsumen akan meningkat.

- Kedua variabel kinerja memiliki kekuatan pengaruh yang hampir sama besar (dapat dilihat dari besar koefisien regresinya), namun Variabel kinerja 43 memiliki kekuatan pengaruh yang sedikit lebih tinggi. 


\section{B. Pengolahan Kuesioner Penelitian : Pengujian Hipotesis Rata-rata}

Pengujian hipotesis dilakukan untuk mengetahui apakah terjadi kesenjangan antara tingkat kepentingan konsumen dan kinerja yang diberikan oleh RM. Swieke Ibu Kristina.

Struktur Hipotesis:

Ho : $\mu_{1}=\mu_{2}$ (tidak ada perbedaan antara tingkat kinerja RM. Swieke Ibu Kristina dengan tingkat kepentingan, sehingga konsumen puas)

Hi : $\mu_{1}<\mu_{2}$ (tingkat kinerja RM. Swieke Ibu Kristina lebih rendah daripada tingkat kepentingan, sehingga konsumen tidak puas)

Keterangan :

Sampel 1 : tingkat kinerja

Sampel 2 : tingkat kepentingan

Taraf nyata: $\alpha=0.05$

Statistik uji: Uji Normal

$$
Z_{\text {hitung }}=Z=\frac{\left(\bar{x}_{1}-\bar{x}_{2}\right)-\left(\mu_{1}-\mu_{2}\right)}{\sqrt{\frac{\mathrm{s}_{1}^{2}}{\mathrm{n}_{1}}+\frac{\mathrm{s}_{2}^{2}}{\mathrm{n}_{2}}}}=\frac{(3.160-3.294)-(0)}{\sqrt{\frac{0.135}{119}+\frac{0.243}{119}}}=-2.384
$$

Wilayah Kritis : dari tabel distribusi Normal dengan $\alpha=0.05=-1.645$

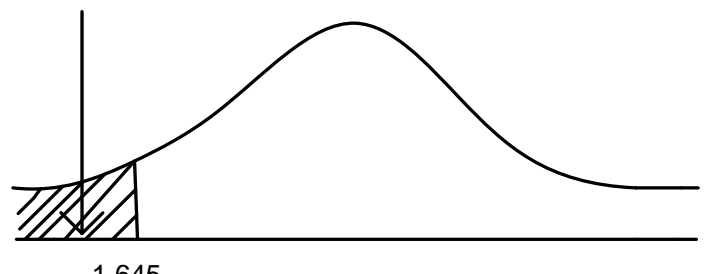

$-1.645$

Gambar 1. Wilayah Kritis Uji Normal

Keputusan:

Jika hasil $\mathrm{Z}$ hitung > dari $\mathrm{Z}$ tabel maka terima $\mathrm{H}_{0}$, konsumen $\mathrm{RM}$. Swieke Ibu Kristina merasa puas, dan sebaliknya.

Tabel 4. Hasil Pengujian Hipotesis Rata-rata

\begin{tabular}{|c|c|c|c|c|c|c|c|c|}
\hline \multirow{2}{*}{ No. } & \multirow{2}{*}{ Var } & \multicolumn{2}{|c|}{ Kinerja } & \multicolumn{2}{c|}{ Kepentingan } & \multirow{2}{*}{$\mathrm{Z}$} & \multirow{2}{*}{ Keputusan } & Kesimpulan \\
\cline { 3 - 6 } & & $\begin{array}{c}\text { Rata- } \\
\text { rata }\end{array}$ & Variansi & $\begin{array}{c}\text { Rata- } \\
\text { rata }\end{array}$ & Variansi & hitung & & \\
\hline 1 & 1 & 3.160 & 0.135 & 3.294 & 0.243 & -2.384 & Tolak Ho & Konsumen Tidak Puas \\
\hline 2 & 2 & 2.681 & 0.389 & 2.941 & 0.378 & -3.246 & Tolak Ho & Konsumen Tidak Puas \\
\hline 3 & 3 & 3.118 & 0.105 & 3.244 & 0.220 & -2.414 & Tolak Ho & Konsumen Tidak Puas \\
\hline 4 & 4 & 3.134 & 0.117 & 3.160 & 0.356 & -0.400 & Terima Ho & Konsumen Puas \\
\hline 5 & 5 & 3.336 & 0.225 & 3.445 & 0.249 & -1.731 & Tolak Ho & Konsumen Tidak Puas \\
\hline 6 & 6 & 3.126 & 0.111 & 3.042 & 0.515 & 1.158 & Terima Ho & Konsumen Puas \\
\hline
\end{tabular}


Tabel 4. Hasil Pengujian Hipotesis Rata-rata (Lanjutan)

\begin{tabular}{|c|c|c|c|c|c|c|c|c|}
\hline \multirow[b]{2}{*}{ No. } & \multirow[b]{2}{*}{ Var } & \multicolumn{2}{|c|}{ Kinerja } & \multicolumn{2}{|c|}{ Kepentingan } & \multirow{2}{*}{$\begin{array}{c}\mathrm{Z} \\
\text { hitung }\end{array}$} & \multirow[b]{2}{*}{ Keputusan } & \multirow[b]{2}{*}{ Kesimpulan } \\
\hline & & $\begin{array}{c}\text { Rata- } \\
\text { rata }\end{array}$ & Variansi & $\begin{array}{c}\text { Rata- } \\
\text { rata }\end{array}$ & Variansi & & & \\
\hline 7 & 7 & 3.303 & 0.213 & 3.504 & 0.252 & -3.227 & Tolak Ho & Konsumen Tidak Puas \\
\hline 8 & 8 & 3.092 & 0.085 & 3.437 & 0.248 & -6.516 & Tolak Ho & Konsumen Tidak Puas \\
\hline 9 & 9 & 3.101 & 0.091 & 3.429 & 0.247 & -6.146 & Tolak Ho & Konsumen Tidak Puas \\
\hline 10 & 10 & 3.109 & 0.098 & 3.370 & 0.269 & -4.691 & Tolak Ho & Konsumen Tidak Puas \\
\hline 11 & 11 & 3.050 & 0.099 & 3.303 & 0.230 & -4.796 & Tolak Ho & Konsumen Tidak Puas \\
\hline 12 & 12 & 3.017 & 0.135 & 3.008 & 0.313 & 0.137 & Terima Ho & Konsumen Puas \\
\hline 13 & 13 & 2.933 & 0.182 & 3.109 & 0.200 & -3.116 & Tolak Ho & Konsumen Tidak Puas \\
\hline 14 & 14 & 2.891 & 0.251 & 3.126 & 0.365 & -3.270 & Tolak Ho & Konsumen Tidak Puas \\
\hline 15 & 15 & 3.286 & 0.206 & 3.538 & 0.268 & -3.997 & Tolak Ho & Konsumen Tidak Puas \\
\hline 16 & 16 & 2.966 & 0.219 & 2.723 & 0.422 & 3.319 & Terima Ho & Konsumen Puas \\
\hline 17 & 17 & 3.050 & 0.099 & 3.328 & 0.222 & -5.337 & Tolak Ho & Konsumen Tidak Puas \\
\hline 18 & 18 & 3.050 & 0.082 & 3.261 & 0.194 & -4.359 & Tolak Ho & Konsumen Tidak Puas \\
\hline 19 & 19 & 3.067 & 0.063 & 3.336 & 0.259 & -5.168 & Tolak Ho & Konsumen Tidak Puas \\
\hline 20 & 20 & 3.193 & 0.157 & 3.471 & 0.251 & -4.733 & Tolak Ho & Konsumen Tidak Puas \\
\hline 21 & 21 & 3.134 & 0.253 & 3.462 & 0.251 & -5.038 & Tolak Ho & Konsumen Tidak Puas \\
\hline 22 & 22 & 2.244 & 0.643 & 2.966 & 0.440 & -7.575 & Tolak Ho & Konsumen Tidak Puas \\
\hline 23 & 25 & 3.143 & 0.174 & 3.454 & 0.250 & -5.207 & Tolak Ho & Konsumen Tidak Puas \\
\hline 24 & 26 & 3.118 & 0.105 & 3.412 & 0.244 & -5.431 & Tolak Ho & Konsumen Tidak Puas \\
\hline 25 & 27 & 3.218 & 0.189 & 3.479 & 0.252 & -4.280 & Tolak Ho & Konsumen Tidak Puas \\
\hline 26 & 28 & 3.168 & 0.141 & 3.471 & 0.251 & -5.269 & Tolak Ho & Konsumen Tidak Puas \\
\hline 27 & 29 & 2.605 & 0.343 & 3.361 & 0.301 & -10.287 & Tolak Ho & Konsumen Tidak Puas \\
\hline 28 & 30 & 3.092 & 0.119 & 3.403 & 0.243 & -5.644 & Tolak Ho & Konsumen Tidak Puas \\
\hline 29 & 31 & 3.143 & 0.123 & 3.403 & 0.243 & -4.696 & Tolak Ho & Konsumen Tidak Puas \\
\hline 30 & 32 & 3.067 & 0.080 & 3.412 & 0.244 & -6.598 & Tolak Ho & Konsumen Tidak Puas \\
\hline 31 & 33 & 3.101 & 0.091 & 3.471 & 0.251 & -6.890 & Tolak Ho & Konsumen Tidak Puas \\
\hline 32 & 34 & 2.706 & 0.328 & 3.328 & 0.256 & -8.876 & Tolak Ho & Konsumen Tidak Puas \\
\hline 33 & 35 & 3.092 & 0.085 & 3.462 & 0.251 & -6.966 & Tolak Ho & Konsumen Tidak Puas \\
\hline 34 & 36 & 3.042 & 0.108 & 3.067 & 0.148 & -0.543 & Terima Ho & Konsumen Puas \\
\hline 35 & 37 & 3.025 & 0.093 & 3.118 & 0.156 & -2.024 & Tolak Ho & Konsumen Tidak Puas \\
\hline 36 & 38 & 2.916 & 0.213 & 3.269 & 0.215 & -5.882 & Tolak Ho & Konsumen Tidak Puas \\
\hline 37 & 39 & 2.908 & 0.169 & 3.361 & 0.233 & -7.807 & Tolak Ho & Konsumen Tidak Puas \\
\hline 38 & 40 & 3.042 & 0.058 & 3.353 & 0.230 & -6.322 & Tolak Ho & Konsumen Tidak Puas \\
\hline 39 & 41 & 3.017 & 0.068 & 3.218 & 0.291 & -3.675 & Tolak Ho & Konsumen Tidak Puas \\
\hline 40 & 42 & 2.605 & 0.343 & 3.202 & 0.247 & -8.475 & Tolak Ho & Konsumen Tidak Puas \\
\hline 41 & 43 & 2.655 & 0.346 & 3.168 & 0.209 & -7.505 & Tolak Ho & Konsumen Tidak Puas \\
\hline 42 & 44 & 2.899 & 0.227 & 3.277 & 0.219 & -6.176 & Tolak Ho & Konsumen Tidak Puas \\
\hline 43 & 45 & 2.370 & 0.320 & 2.521 & 0.438 & -1.895 & Tolak Ho & Konsumen Tidak Puas \\
\hline
\end{tabular}

Hasil pengujian hipotesis rata-rata diatas menunjukkan bahwa hanya 5 variabel kinerja yang telah memuaskan konsumen. Perhatian lebih difokuskan pada 2 variabel kinerja yang terbukti signifikan mempengaruhi frekwensi kedatangan konsumen yaitu variabel 30 dan 43, dimana kedua variabel tersebut juga belum memuaskan konsumen. 


\section{Pengolahan Kuesioner Penelitian : Profil Konsumen}

Tabel dibawah ini menunjukkan besar persentase profil konsumen yang menjadi responden penelitian.

Tabel 5. Profil Konsumen

\begin{tabular}{|c|c|c|}
\hline Profil & Jumlah & $\%$ \\
\hline \multicolumn{3}{|c|}{ Usia konsumen. } \\
\hline $18-25$ tahun & 44 & $36.97 \%$ \\
\hline $26-32$ tahun & 29 & $24.37 \%$ \\
\hline $33-40$ tahun & 16 & $13.45 \%$ \\
\hline Diatas 40 tahun & 30 & $25.21 \%$ \\
\hline \multicolumn{3}{|c|}{ Tujuan datang ke RM. Swieke Ibu Kristina. } \\
\hline Makan di tempat & 108 & $64.67 \%$ \\
\hline Dibungkus & 48 & $28.74 \%$ \\
\hline Bertemu rekan kerja & 9 & $5.39 \%$ \\
\hline Lainnya & 2 & $1.20 \%$ \\
\hline \multicolumn{3}{|c|}{ Rumah makan penjual swieke } \\
\hline RM. Cahaya Baru & 69 & $57.98 \%$ \\
\hline RM. Aman & 32 & $26.89 \%$ \\
\hline Lainnya & 19 & $15.13 \%$ \\
\hline \multicolumn{3}{|c|}{$\begin{array}{l}\text { Yang menemani saat berkunjung } \\
\text { ke RM. Swieke Ibu Kristina }\end{array}$} \\
\hline Keluarga & 77 & $64.71 \%$ \\
\hline Relasi agama & 4 & $3.36 \%$ \\
\hline Teman kantor & 19 & $15.97 \%$ \\
\hline Teman sekolah & 5 & $4.20 \%$ \\
\hline Lainnya & 14 & $11.76 \%$ \\
\hline \multicolumn{3}{|c|}{ Jumlah anggota kelompok yang datang bersama } \\
\hline 1 orang & 12 & $10.08 \%$ \\
\hline $2-3$ orang & 46 & $38.66 \%$ \\
\hline 4-5 orang & 48 & $40.34 \%$ \\
\hline$\geq 6$ orang & 13 & $10.92 \%$ \\
\hline \multicolumn{3}{|c|}{ Frekwensi makan bersama kelompok per bulan } \\
\hline 1 kali & 34 & $28.57 \%$ \\
\hline $2-4$ kali & 79 & $66.39 \%$ \\
\hline $5-7$ kali & 3 & $2.52 \%$ \\
\hline$\geq 8$ kali & 3 & $2.52 \%$ \\
\hline \multicolumn{3}{|c|}{$\begin{array}{l}\text { Pengambil keputusan untuk memilih } \\
\text { RM. Swieke Ibu Kristina }\end{array}$} \\
\hline Keluarga & 72 & $60.50 \%$ \\
\hline Relasi agama & 4 & $3.36 \%$ \\
\hline Teman kantor & 18 & $15.13 \%$ \\
\hline Teman sekolah & 5 & $4.20 \%$ \\
\hline Lainnya & 20 & $16.81 \%$ \\
\hline
\end{tabular}

\begin{tabular}{|c|c|c|}
\hline Profil & Jumlah & $\%$ \\
\hline \multicolumn{3}{|c|}{ Lokasi tempat tinggal konsumen. } \\
\hline Karawang Barat & 70 & $58.82 \%$ \\
\hline Karawang Timur & 26 & $21.85 \%$ \\
\hline Lainnya & 23 & $19.33 \%$ \\
\hline \multicolumn{3}{|c|}{$\begin{array}{l}\text { Pengetahuan mengenai } \\
\text { keberadaan RM. Swieke Ibu Kristina. }\end{array}$} \\
\hline Teman & 49 & $41.18 \%$ \\
\hline Promosi & 2 & $1.68 \%$ \\
\hline Saudara & 33 & $27.73 \%$ \\
\hline Kebetulan Lewat & 27 & $22.69 \%$ \\
\hline Lainnya & 8 & $6.72 \%$ \\
\hline \multicolumn{3}{|c|}{ Alasan utama pemilihan } \\
\hline Murah & 19 & $15.97 \%$ \\
\hline Variasi menu & 4 & $3.36 \%$ \\
\hline Pelayanan cepat & 13 & $10.92 \%$ \\
\hline Dekat tempat tinggal & 6 & $5.04 \%$ \\
\hline Kualitas makanan & 4 & $3.36 \%$ \\
\hline Rasa lezat & 71 & $59.66 \%$ \\
\hline Lainnya & 2 & $1.68 \%$ \\
\hline \multicolumn{3}{|c|}{$\begin{array}{c}\text { Harapan saat datang } \\
\text { ke RM. Swieke Ibu Kristina }\end{array}$} \\
\hline Porsi banyak & 24 & $20.17 \%$ \\
\hline Kelezatan rasa & 95 & $79.83 \%$ \\
\hline \multicolumn{3}{|c|}{$\begin{array}{l}\text { Faktor penghambat yang menyebabkan } \\
\text { pembatalan ke RM. Swieke Ibu Kristina }\end{array}$} \\
\hline Hujan & 52 & $35.62 \%$ \\
\hline Macet & 18 & $12.33 \%$ \\
\hline Lokasi jauh & 26 & $17.81 \%$ \\
\hline Parkir penuh & 43 & $29.45 \%$ \\
\hline Lainnya & 7 & $4.79 \%$ \\
\hline \multicolumn{3}{|c|}{ Frekwensi terjadinya faktor penghambat } \\
\hline Tidak pernah & 25 & $21.01 \%$ \\
\hline Jarang & 76 & $63.87 \%$ \\
\hline Sering & 11 & $9.24 \%$ \\
\hline Sering sekali & 7 & $5.88 \%$ \\
\hline \multicolumn{3}{|c|}{$\begin{array}{l}\text { Kesediaan makan kembali } \\
\text { ke RM. Swieke Ibu Kristina }\end{array}$} \\
\hline Ya & 116 & $97.48 \%$ \\
\hline Tidak & 3 & $2.52 \%$ \\
\hline \multicolumn{3}{|c|}{ Kesediaan mengajak teman atau kerabat } \\
\hline $\mathrm{Ya}$ & 116 & $97.48 \%$ \\
\hline Tidak & 3 & $2.52 \%$ \\
\hline
\end{tabular}


Tabel profil responden diatas digunakan untuk membantu RM. Swieke Ibu Kristina menentukan target pasar yang tepat bagi rumah makannya dan mempertajam usulan penelitian. Terlihat bahwa mayoritas konsumen datang ke RM. Swieke Ibu Kristina dengan tujuan untuk makan di tempat bersama keluarga dengan anggota kelompok yang cukup banyak (2-5 orang), memilih RM. Swieke Ibu Kristina karena kelezatan rasa makanan, dan merupakan pelanggan tetap RM. Swieke Ibu Kristina. Berdasarkan target pasar diatas, sebaiknya RM. Swieke Ibu Kristina memposisikan diri sebagai rumah makan keluarga yang mementingkan kualitas rasa.

\section{Pengolahan Kuesioner Penelitian : Prioritas Perbaikan}

Prioritas perbaikan diberikan dengan memberikan perhatian khusus pada variabel yang secara signifikan berpengaruh terhadap frekwensi kedatangan konsumen per bulan, dilanjutkan dengan hasil pengujian hipotesis rata-rata.

Tabel 6. Prioritas Perbaikan

\begin{tabular}{|c|c|c|c|c|}
\hline \multirow{2}{*}{ Regresi Berganda } & \multicolumn{2}{|c|}{ Pengujian Hipotesis Rata-rata } & \multirow{2}{*}{ Variabel } & \multirow{2}{*}{ Prioritas } \\
\hline & Z hitung & Keputusan & & \\
\hline \multirow{2}{*}{$\begin{array}{c}\text { Signifikan } \\
\text { Berpengaruh }\end{array}$} & -7.505 & Konsumen Tidak Puas & 43 & 1 \\
\hline & -5.644 & Konsumen Tidak Puas & 30 & 2 \\
\hline \multirow{27}{*}{$\begin{array}{l}\text { Tidak Signifikan } \\
\text { Berpengaruh }\end{array}$} & -10.287 & Konsumen Tidak Puas & 29 & 3 \\
\hline & -8.876 & Konsumen Tidak Puas & 34 & 4 \\
\hline & -8.475 & Konsumen Tidak Puas & 42 & 5 \\
\hline & -7.807 & Konsumen Tidak Puas & 39 & 6 \\
\hline & -7.575 & Konsumen Tidak Puas & 22 & 7 \\
\hline & -6.966 & Konsumen Tidak Puas & 35 & 8 \\
\hline & -6.890 & Konsumen Tidak Puas & 33 & 9 \\
\hline & -6.598 & Konsumen Tidak Puas & 32 & 10 \\
\hline & -6.516 & Konsumen Tidak Puas & 8 & 11 \\
\hline & -6.322 & Konsumen Tidak Puas & 40 & 12 \\
\hline & -6.176 & Konsumen Tidak Puas & 44 & 13 \\
\hline & -6.146 & Konsumen Tidak Puas & 9 & 14 \\
\hline & -5.882 & Konsumen Tidak Puas & 38 & 15 \\
\hline & -5.431 & Konsumen Tidak Puas & 26 & 16 \\
\hline & -5.337 & Konsumen Tidak Puas & 17 & 17 \\
\hline & -5.269 & Konsumen Tidak Puas & 28 & 18 \\
\hline & -5.207 & Konsumen Tidak Puas & 25 & 19 \\
\hline & -5.168 & Konsumen Tidak Puas & 19 & 20 \\
\hline & -5.038 & Konsumen Tidak Puas & 21 & 21 \\
\hline & -4.796 & Konsumen Tidak Puas & 11 & 22 \\
\hline & -4.733 & Konsumen Tidak Puas & 20 & 23 \\
\hline & -4.696 & Konsumen Tidak Puas & 31 & 24 \\
\hline & -4.691 & Konsumen Tidak Puas & 10 & 25 \\
\hline & -4.359 & Konsumen Tidak Puas & 18 & 26 \\
\hline & -4.280 & Konsumen Tidak Puas & 27 & 27 \\
\hline & -3.997 & Konsumen Tidak Puas & 15 & 28 \\
\hline & -3.675 & Konsumen Tidak Puas & 41 & 29 \\
\hline
\end{tabular}


USULAN STRATEGI BAURAN PEMASARAN (Yulianti, dkk.)

Tabel 6. Prioritas Perbaikan (Lanjutan)

\begin{tabular}{|c|c|c|c|c|}
\hline \multirow{2}{*}{ Regresi Berganda } & \multicolumn{2}{|c|}{ Pengujian Hipotesis Rata-rata } & \multirow{2}{*}{ Variabel } & \multirow{2}{*}{ Prioritas } \\
\hline & Z hitung & Keputusan & & \\
\hline \multirow{14}{*}{$\begin{array}{c}\text { Tidak Signifikan } \\
\text { Berpengaruh }\end{array}$} & -3.270 & Konsumen Tidak Puas & 14 & 30 \\
\hline & -3.246 & Konsumen Tidak Puas & 2 & 31 \\
\hline & -3.227 & Konsumen Tidak Puas & 7 & 32 \\
\hline & -3.116 & Konsumen Tidak Puas & 13 & 33 \\
\hline & -2.414 & Konsumen Tidak Puas & 3 & 34 \\
\hline & -2.384 & Konsumen Tidak Puas & 1 & 35 \\
\hline & -2.024 & Konsumen Tidak Puas & 37 & 36 \\
\hline & -1.895 & Konsumen Tidak Puas & 45 & 37 \\
\hline & -1.731 & Konsumen Tidak Puas & 5 & 38 \\
\hline & -0.543 & Konsumen Puas & 36 & \multirow{5}{*}{$\begin{array}{c}\text { Tidak } \\
\text { diperbaik }\end{array}$} \\
\hline & -0.400 & Konsumen Puas & 4 & \\
\hline & 0.137 & Konsumen Puas & 12 & \\
\hline & 1.158 & Konsumen Puas & 6 & \\
\hline & 3.319 & Konsumen Puas & 16 & \\
\hline
\end{tabular}

Terdapat 38 perbaikan yang perlu dilakukan oleh RM. Swieke Ibu Kristina bila ingin meningkatkan frekwensi kedatangan konsumen dan memuaskan konsumen.

\section{Kesimpulan dan Saran}

- Penelitian ini menggunakan teori pemasaran 7P dan perilaku organisasi untuk membantu RM. Swieke Ibu Kristina agar dapat meningkatkan frekwensi kedatangan konsumen.

- Berdasarkan profil konsumen, target pasar yang diusulkan bagi RM. Swieke Ibu Kristina adalah konsumen yang bertujuan untuk makan di tempat, datang bersama keluarga dengan anggota kelompok yang cukup banyak (2-5 orang). Karena mayoritas konsumen memilih RM. Swieke Ibu Kristina karena kelezatan rasa makanan, maka sebaiknya RM. Swieke Ibu Kristina memposisikan diri sebagai rumah makan keluarga yang mementingkan kualitas rasa.

- Hasil pengolahan metode Regresi Berganda menunjukkan bahwa variabel yang terbukti signifikan berpengaruh terhadap frekwensi kedatangan konsumen adalah kinerja Kecukupan jumlah meja dan kursi (Var 43) dan Ketepatan dalam perhitungan harga (Var 33). Variabel kinerja 43 memiliki pengaruh yang lebih besar terhadap frekwensi kedatangan konsumen dibandingkan Variabel kinerja 33.

Variabel kinerja 43 dan kinerja 33 hanya dapat menjelaskan tentang frekwensi kedatangan konsumen sebesar $15.1 \%$. Karena itu disarankan agar dilakukan penelitian lebih lanjut untuk membantu RM. Swieke Ibu Kristina, misalnya melakukan perbandingan langsung antara RM. Swieke Ibu Kristina dengan rumah makan pesaing yaitu RM. Cahaya Baru.

- RM. Swieke Ibu Kristina dapat meningkatkan frekwensi kedatangan konsumen dengan cara melakukan memberikan prioritas perbaikan utama pada variabel kinerja RM yang terbukti berpengaruh secara signifikan (hasil pengolahan metode Regresi Berganda) dan variabelvariabel yang belum memuaskan konsumen (hasil pengolahan pengujian hipotesis rata-rata). Berikut adalah usulan untuk 10 prioritas utama:

- Prioritas 1: Target yang diusulkan adalah keluarga dengan jumlah anggota kelompok kedatangan cukup banyak, sehingga disarankan pihak rumah makan menyediakan meja dengan ukuran bervariasi yang dapat dengan mudah digabungkan bila dibutuhkan, juga menyediakan kursi-kursi tambahan. Ketepatan ukuran tinggi kursi dan meja juga sangat dipentingkan untuk kenyamanan konsumen. 
- Prioritas 2: Mengadakan pelatihan tentang penjelasan mendetail mengenai seluruh menu restoran yang ada (rasa, bahan yang digunakan, cara memasak, cara penyajian, dll) untuk mengantisipasi konsumen yang kritis menanyakan mengenai menu restoran.

- Prioritas 3: Penggunaan pakaian seragam bagi karyawan di RM. Swieke Ibu Kristina agar terlihat lebih rapi dan profesional.

- Prioritas 4: RM. Swieke Ibu Kristina sebaiknya membuat menu pemesanan yang dicetak sehingga karyawan cukup hanya menuliskan jumlah porsi pesanan. Hal ini untuk memudahkan konsumen pada saat pembayaran juga untuk meminimasi kesalahan yang terjadi (baik jenis makanan, jumlah pemesanan dan harga yang diberikan), terutama mengingat konsumen rumah makan ini umumnya dalam bentuk kelompok yang besar sehingga kesalahan mungkin sekali terjadi.

- Prioritas 5: Faktor kebersihan rumah makan sangatlah penting bagi konsumen. RM. Swieke Ibu Kristina berada di kawasan kuliner di pinggir jalan raya yang cukup berdebu. Untuk mengatasi hal tersebut, diusulkan bahwa RM ini memakai tirai panjang untuk mencegah debu yang masuk dan sering membersihkan debu di lingkungan rumah makan.

- Prioritas 6: Selain untuk mengetahui keberadaan suatu rumah makan, spanduk atau papan nama juga menjadi salah satu daya tarik konsumen untuk berkunjung . RM. Swieke Ibu Kristina disarankan merancang papan nama/spanduk yang unik dan menarik, yang menonjolkan positioningnya sebagai rumah makan keluarga yang menyajikan hidangan swieke yang lezat.

- Prioritas 7: Disarankan agar pihak RM. Swieke Ibu Kristina menggunakan alat bantu (seperti kalkulator atau mesin kasir sederhana) dan membuat kotak penyimpanan uang yang sudah ditata menurut nominalnya agar lebih cepat dan tepat dalam perhitungan tagihan, juga pemberian uang kembali.

- Prioritas 8: Kebersihan adalah syarat mutlak yang harus dimiliki oleh sebuah rumah makan, karenanya pihak rumah makan perlu sangat menjaga proses saat membersihkan bahan makanan, proses memasak hingga penyajian agar kebersihan selalu terjamin. Pemilik RM. Swieke Ibu Kristina perlu melakukan pengecekan secara berkala untuk menjamin kebersihan rumah makannya.

- Prioritas 9: Untuk menjaga kenyamanan konsumen saat makan, disarankan agar pihak rumah makan menempelkan poster dilarang merokok dan menyediakan kipas angin untuk melancarkan sirkulasi udara di tempat makan.

- Prioritas 10: Area parkir tempat kuliner yang ditempati oleh RM. Swieke Ibu Kristina sebetulnya sudah cukup luas, namun pada waktu-waktu tertentu seringkali penuh sehingga membuat konsumen yang ingin berkunjung ke RM. Swieke Ibu Kristina mengalami kesulitan untuk parkir. Masalah ini juga ditunjukkan pada profil konsumen. Untuk mengatasi hal tersebut, bila memungkinkan disarankan agar RM.Swieke Ibu Kristina memiliki tempat parkir tersendiri, tidak berbagi dengan tempat kuliner lainnya.

\section{Daftar Pustaka}

Anderson, D., Sweeney, D.J., Williams, T.A., (2008), Statistics for Business \& Economics, $10^{\text {th }}$ edition, Thomson South-Western

Hair, Anderson, Tatham \& Black, (2006), Multivariate Data Analysis, Prentice-Hall International, Inc., USA

Kotler, Amstrong, (2001), Prinsip-prinsip Pemasaran, Jilid 1, Edisi ke-8, Erlangga.

Kotler, P., Keller, K., (2009), Manajemen Pemasaran, Edisi Ke-13, Erlangga.

Sugiyono, (2010), Metode Penelitian Administrasi, CV. ALFABETA, Bandung

Supranto, J., (2001), Pengukuran Tingkat Kepuasan Pelanggan., PT Rineka Cipta, Jakarta 